\title{
EROSION WEAR OF DUCTILE MATERIALS: A REVIEW
}

\author{
Bharat Singh Chahar, Siddhartha, Ananat Krishna Pun \\ Department of Mechanical Engineering, \\ NIT Hamirpur (H.P.)-177005 \\ chaharbharat007@gmail.com
}

\begin{abstract}
Erosion wear is a surface damage phenomenon which occurs due to repeated impact of high speed small erodent particle strikes the target material that causes removal of material from target surface. In case of ductile materials, indentation of erodent particle results in erosion wear. The objective of this paper is to give the brief review of erosion of ductile materials by explaining various erosion wear models developed by various researchers. It also explains the different ductile erosion wear mechanism and the parameters which affect the erosion wear.
\end{abstract}

Keywords- Erosion wear; ductile; erosion mechanism, Finnie's model.

\section{INTRODUCTION}

Solid particle erosion occurs by the impingement of the solid particles to the target material. It is indeed a difficult process to examine and understand, but researchers have worked exclusively in this area and have developed erosion wear models to predict the rate of material removal from the surface of a body. In this work the author has attempted to classify and discuss various mathematical models developed over the years according to the material behavior (ductile) towards the impact of solid particles. Solid particle erosion is undesirable in almost all industrial applications such as erosion of machine parts, surface damage of turbine blades, erosion of slurry carrying pipelines, solid particle erosion in fluidized bed combustion system, etc. erosion has useful application in sand blasting, abrasive machining, erosive drilling of hard target materials, thus emphasizing the importance of erosion wear models for predicting the material reaction to erosion wear situation and to determine the rate of material removal from the surface of a body. This review article is written so that an understanding is created towards the development of an erosion wear model and the reader comes to know about the interesting facts, parameters and various assumptions made by the researchers over a period of time and also they will come to know about the fundamentals that are

required to be known before taking up the development of a theoretical erosion wear model. This review article will definitely benefit researchers who are working in this particular area.

There are two parameters i.e. erosion rate and erosion efficiency, which are frequently used during the study of erosion wear models. The concept of erosion efficiency is given by G. Sundarrajan (1). The dimensionless erosion rate (E) is defined as the ratio of mass loss suffered by erodent surface to the mass of erodent particle causing the mass loss. The parameter erosion efficiency $(\eta)$ is defined as the ratio of actual volume removed to the crater volume.

\section{EROSION WEAR MODELS}

Two basic erosion mechanisms have been observed for erosion of ductile materials i.e. cutting erosion and deformation (ploughing erosion). In cutting erosion, the detachment of crater lips occurs by one or several impacts of the micromachining, ploughing of lip formation type. In deformation erosion, the detachment of the material occurs by the several fragmentations due to several impacts of the indentation type. Cutting and deformation erosion dominate at grazing and normal incidence, respectively.

\section{A. Finnie (1958)}

Finnie (2) was the first to derive the single particle cutting erosion wear model. The erosion behavior of ductile materials was studied by solving the equation of motion for a rigid abrasive particle interacting with the surface. Volume of material removal was estimated from the particle trajectory.

Volume of surface material removed $=$ area swept out by particle tip $\times$ width of cutting face.

Major assumptions are:

- The impact particle is harder than the target surface and does not breakup.

- Material is removed in a same way as removed by a single point cutting tool.

\section{B. Bitter (1962)}

According to Bitter (3), in erosion two types of wear occur simultaneously i.e. deformation and cutting wear and their effects can be superimposed. Bitter's model is an extensionto Finnie's model as it introduced the concept of threshold erosion rate and energy dissipation. Deformation wear occurs due to repeated collisions of particle on the target material surface; whereas cutting wear when particle strikes the surface 
at an acute angle. The material is subjected to deform due to shear. At normal impact, only deformation wear occurs.

The results of this model are same as that of Finnie's model for soft ductile materials with no erosion at $90^{\circ}$ but for brittle materials it shows maximum erosion at $90^{\circ}$.This model includes more target material and impacting particle properties as compared to Finnie's model.

In this model it is assumed that the impact particle is rigid and it does not erode (3).

\section{G. L. Sheldon and Ashok Kanhere (1972)}

The impingement erosion process was studied by investigating the effect of impact of relatively large single particle on an aluminum surface.

A mathematical model is presented based on indentation hardness theory. This model is valid for relatively low impact velocities.

The basic hypothesis in development of this model (4) is that the material removed is flowed out around the sides of the cavity by the advancing particle until the displaced material is strained enough to break off. Amount of material removed is assumed to be related to the depth of penetration of the particle.

Material removed per particle or per gram of particle is given as:

$$
\epsilon_{m} \sim q^{a}=\frac{d^{3} v^{3}\left(\rho_{p}\right)^{3 / 2}}{H_{V}^{3 / 2}}
$$

The results match closely with experimental data.

It does not provide a good insight into the mechanism of erosion, inertia and strain rate effects and hardness exponent values are not well established.

D. G. P. Tilly (1972)

In this paper (5) erosion is treated as a two stage process. The first stage is produced by the impacting particles to produce an indentation on the target material so that chips are removed. The second stage is due to the breaking up of impacting particles so that fragments are projected radially from the point of impact and produce secondary damage as shown in fig (1).
Numerical equation for the first stage or primary erosion:

$$
\epsilon_{1}=\widehat{\epsilon}_{1}\left(\frac{V}{V_{V E S}}\right)^{2}\left[1-\left(\frac{d_{0}}{d}\right)^{3 / 2} \frac{V_{0}}{V}\right]^{2}
$$

For secondary erosion it was assumed that erosion is produced only when the particles break up on impact and the amount of erosion is proportional to the initial kinetic energy and the level of fragmentation. The threshold conditions for the secondary process did not seem to be evident.

Numerical equation for the second stage or secondary erosion:

$$
\epsilon_{2}=\widehat{\epsilon}_{2}\left(\frac{V}{V_{v E s}}\right)^{2} F_{d V}
$$

The primary and secondary erosion can be combined to obtain an equation for overall erosion:

$\epsilon=\widehat{\epsilon}_{1}\left(\frac{V}{V_{\text {VES }}}\right)^{2}\left[1-\left(\frac{d_{0}}{d}\right)^{a / 2} \frac{V_{0}}{V}\right]^{2}+\widehat{\epsilon}_{2}\left(\frac{V}{V_{\text {VES }}}\right)^{2} F_{d_{Q} V}(4)$

At impact angles lower than $90^{\circ}$ first stage predominates and at $90^{\circ}$ the second stage predominates.

It was observed that the extent of fragmentation depends on the particle size and velocity. Particles that are too small to break up, cause primary erosion only whereas increase in particle size and velocity causes an increase in secondary erosion.

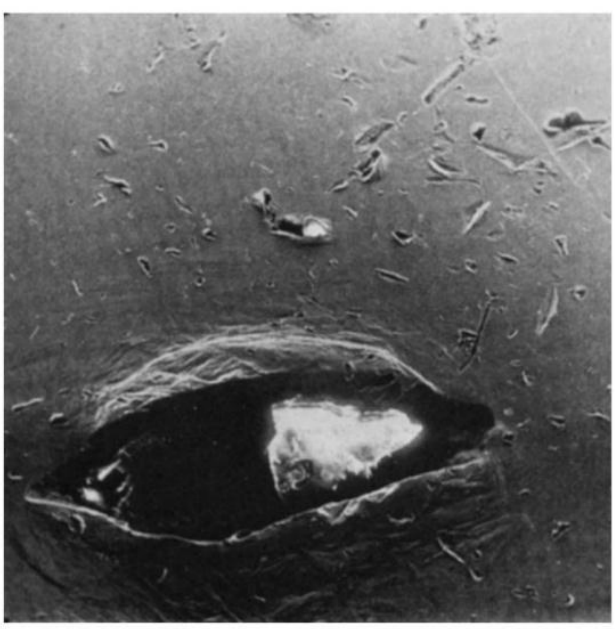

Fig.1.Primary indentation surrounded by secondary damage of H46 steel.

E. W. H. Jennings et al (1976)

Dimensional analysis was employed for the development of mathematical model for the prediction of erosion of ductile 
materials. The erosion was based on an identified erosion mechanism i.e. target melting.

The parameters chosen to characterise the material resistance to melting, physical nature of the erodents and the driving functions are:

1) Resistance to melting - Density, thermal conductivity, melting temperature, enthalpy of melting and molecular weight of target material.

2) Physical nature of erodent particles - roundness.

3) Driving functions - Kinetic energy transferred to the target by the impacting particles.

The erosion model (6) is as follows:

$$
\epsilon_{v}=\left(\frac{k_{T}^{5 / 2}}{R} \frac{G^{1 / 3}}{\rho_{\mathrm{t}}^{1 / 3} k T_{m} \Delta H_{m}}\right) S
$$

This model gives good estimates of the erosion rates and can be used for ranking metals.

\section{F. I. M. Hutchings (1981)}

This paper (7) presents an analytical model for erosion at normal incidence by platelet formation. The suitable criterion assumed is that of critical strain, so it is considered as the property of the material and as a measure of its ductility under erosion.

From critical strain the value for the number of plastic strain cycles required to remove a fragment is deduced.

The target material is assumed to be struck by a large number of spherical projectiles, each travelling at same velocity and causing same pattern of plastic deformation.

For simplicity metal being eroded is considered as a perfectly plastic solid with no work hardening.

Final equation as derived by the author is:

$$
\epsilon=0.033 \frac{\propto \rho_{t} p^{1 / 2} V^{3}}{\Omega_{L}^{2} H_{t}^{3 / 2}}
$$

There is a fair agreement between the theory and experiment. The mechanical properties of metal incorporated are dynamic hardness of metal and ductility of the metal under erosion conditions. The hardness and ductility measured in conventional tests will not correlate with the properties relevant to erosion.

The strain hardening is neglected.
It takes no account of precise mechanism of material removal.

\section{G. Sunderajan (1991)}

In this model (8), the author has emphasized on the correlation that exists between the plastic zone size and the erosion rate. The objective of this paper was to investigate the influence of test and material variables on the extent of the plastic zone that exists beneath the eroded surfaces.

The erosion rate $\epsilon$ is given by:

$$
E \approx L^{a}\left(\frac{\Delta n}{a_{c}}\right)
$$

The main thrust was in developing expression for the plastic zone size. He assumed that the plastic zone was proportional to the diameter (D) of the crater formed by the impact of one particle.

$L=\alpha D$

The general expression for L developed by Sundararajan is:

$L=r C\left(\frac{\rho_{p} V^{2} \sin ^{2} \alpha}{\zeta}\right)^{\alpha}(9)$

\section{H. Siddhartha and Renu Bisht (2012)}

In this work (9), a mechanics based mathematical model is developed for the prediction of erosion wear rate. It presents results based on a particular shape and physical dimensions of the erodent particles. Effects of both the horizontal and vertical components of impact velocity are taken into consideration to find out the erosion wear rate. This model was validated using MATLAB code and taking extensive data from literature.

1. The authors made the following assumptions for the proposed model:

2. Erodent particle is rigid and does not deform during impact.

3. The problem can be treated as quasi-static i.e. dynamic effects such as wave propagation is neglected.

4. Strain rate sensitivity is neglected.

5. The only force assumed to be contact force exerted by the surface.

6. Erodent particles are square pyramidal in shape.

The erosion rate defined as the ratio of target material loss per unit time due to erosion to the mass of erodent causing the loss is expressed as: 
$E_{r}=\frac{1}{6 H_{k}} \times \eta \times p_{k} \times V^{2} \times\left(\frac{2 A \sin \alpha \cos \phi+3 h \cos \alpha}{A \sin \alpha \cos \phi+h \cos \alpha}\right)$

Effects of physical dimensions of the erodent particle are taken into consideration.

It is valid only for impact angles below $90^{\circ}$.

\section{DUCTILE EROSION WEAR MECHANISM}

Erosion wear of ductile materials mainly occurs due to the following mechanism:

1) Deformation and cutting wear mechanism.

2) Micro-machining

3) Platelet mechanism

When erodent particles strike the target surface at an acute angle then the vertical component of velocity leads to deformation wear and the horizontal component leads to cutting wear.

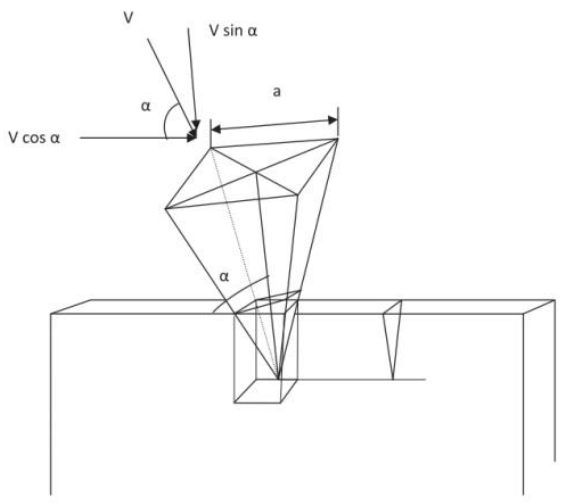

Fig. 2. Velocity components of deformation and cutting wear.

Deformation wear occurs due to continuously repeated impact of erodent particle on the target surface which leads to removal of material from target surface by forming the indentation. Whereas cutting wear occurs, when the cutting force acting on the target surface exceeds the shear strength of the target material. In practice, these two types of wear occur simultaneously so the total erosion wear of ductile material is the combined effect of deformation and cutting wear.

In 1958 Finnie proposed a mathematical model to predict the erosion rate that was based on the assumption that erodent particle removes the material from target surface similar to the tooth of milling cutter or abrasive of grinding wheel. This type of erosion mechanism is called micromachining.

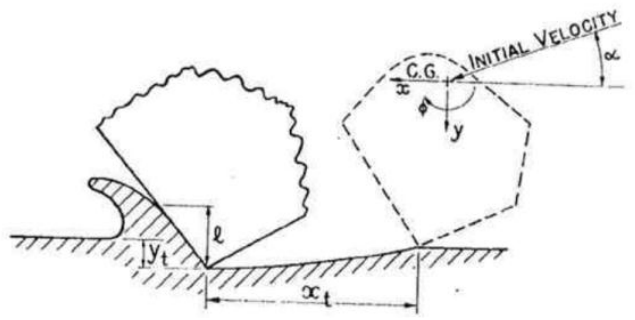

Fig. 3. Micro-machining erosion mechanism

Platelet mechanism of erosion is based on micro- extrusion and forging instead of micro-machining.

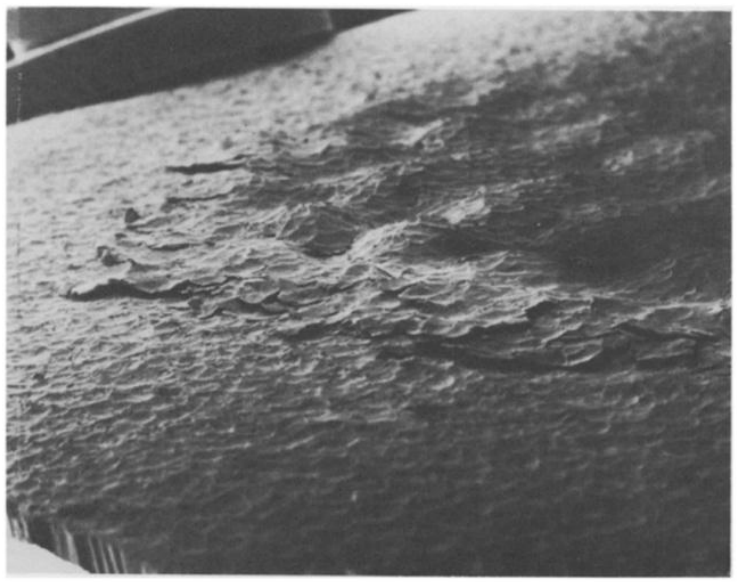

Fig. 4. Platelets at the primary erosion zone of Al.

\section{INFLUENCING FACTORS OF DUCTILE EROSION}

1. Angle of impingement.

2. Particle velocity at impingement.

3. Particle size.

4. Shape of particle and strength.

5. Surface properties.

6. Particle concentration in fluid system.

7. Particle rotation at impingement.

Effect of angle of impingement on erosion 
It has been seen that higher erosion rate is obtained at low angle of impingement. As the value of impingement angle increases, the value of erosion rate decreases for ductile materials.

\section{Particle velocity of impingement}

It has been observed experimentally that volume removed by erosion is proportional nearly to the square of velocity of impingement.

\section{Particle size}

The volume removed due to erosion is independent of erodent particle size for particle larger then $100 \mu \mathrm{m}$. for particle size less than $100 \mu \mathrm{m}$, erosion rate decreases as particle size decreases. The actual physical for this size effect are still not clear.

\section{Shape of particle and strength}

Shape and strength of erodent particle effect the erosion volume and impingement angle. Generally, spherical and abrasive or angular shape erodent particle are used. Abrasive particles leads to higher erosion rate as compare to spherical erodent particle.

\section{Surface properties}

Surface properties of target material greatly influenced the erosion rate. It has been seen that the surface hardness of target material is inversely proportional to the volume removed and prior cold work has no influence on erosion.

\section{Particle concentration in fluid system}

The effect of particle concentration on erosion is not significantly high. No clear and satisfactory explanation available for this effect (10).

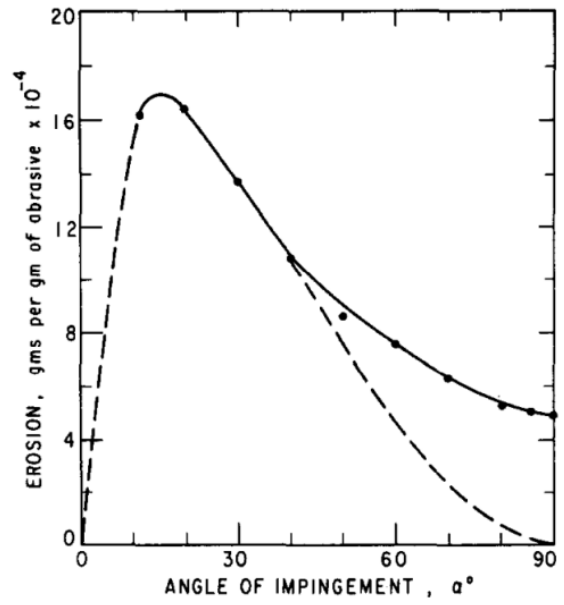

Fig. 5. Erosion rate vs. angle of impingement.

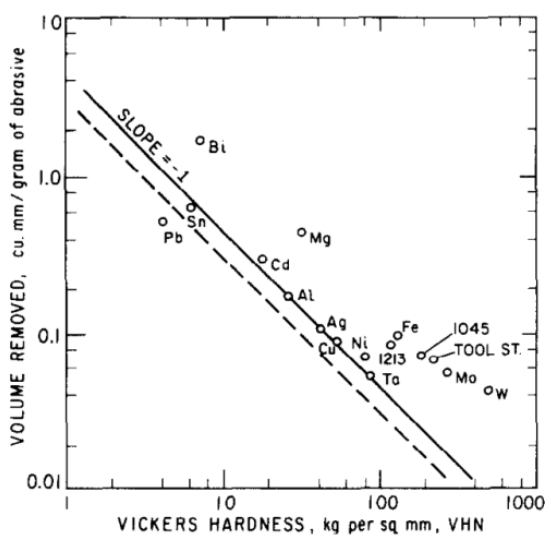

Fig. 6. Effect of hardness of target surface on volume removed.

\section{Effect of particle rotation on impingement}

It has been observed that when the rotated erodent particle strikes the target surface, the resultant velocity of impact is higher as compare to non-spinning or rotating erodent particle which leads to higher erosion rate. A particle with back-spin has a higher resultant velocity at the point of contact with target material (11). 


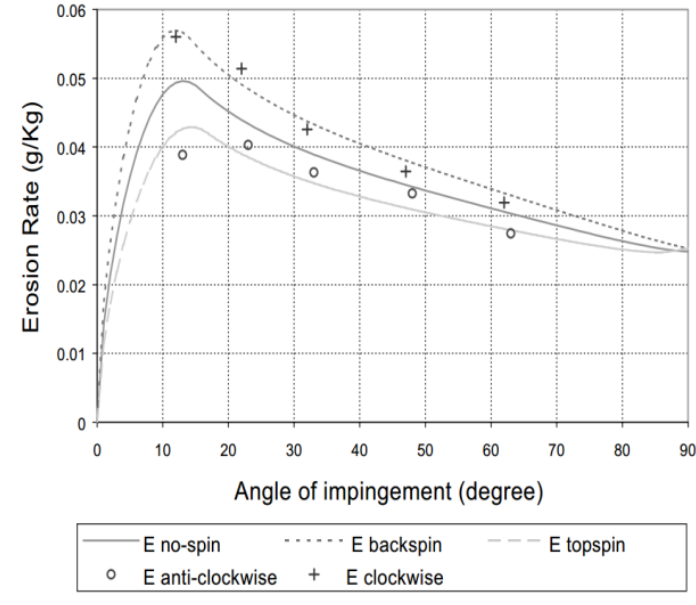

Fig. 7. Effect of particle rotation on erosion rate.

\section{CONCLUSIONS}

This review paper consist different erosion wear models of ductile materials which tells about the chronological development of erosion wear models. It gives the better understanding of different principal mechanism used by different researchers for the development of their models .Every mathematical model is developed based on certain assumptions.

There are two types of erodent particle either spherical or abrasive. Abrasive or angular shape erodent particle leads to higher erosion wear. Higher erosion rate is obtained by abrasive erodent particle due to following reasons:

- Due to irregular shape of abrasive erodent particle, at the time of impact some unbalanced forces act on it which causes rotating effect. Hence the velocity of impingement is higher as compare to spherical erodent particle.

- Effective micro-machining by abrasive erodent particles.

The target materials having good toughness eroded by platelet mechanism of erosion wear. In erosion wear of ductile materials surface properties of target surface such as toughness, hardness and strain hardening coefficient play an important role.

Due to repeated impact of erodent particles on the target surface cause local temperature rise, which soften the surface layers of target material i.e. increase the toughness of target surface layers. Hence erosion rate decreases.

\section{Acknowledgement}

The author would like acknowledge his guide as well as his family and friends for their support and their beliefs which inspired him to do his work effectively.

\section{References}

[1] G. Sudararajan, M. Roy and B. Venkataraman, Erosion efficiency- a new parameter to characterize the dominant erosion micromechanism, Wear, 140 (1990) $369-381$.

[2] I. Finnie, The mechanism of erosion of ductile metals, Proceedings of the Third National Congress on Applied Mechanics, New York, 1958 pp. 527532 .

[3] J.G.A. Bitter, A study of erosion phenomena, Wear, 6 (1963) 5-21.

[4] G.L.Sheldon and Ashok Kanhere, An investigation of impingement erosion using single particles, Wear, 21 (1972) 195-209.

[5] G.P.Tilly, A two stage mechanism of ductile erosion, Wear, 23 (1973) 8796.

[6] W,H.Jennings, W.J.Head and C.R.Manning, Jr, A mechanistic model for the prediction of ductile erosion, Wear, 40 (1976) 93-112.

[7] I.M.Hutchings and R.E.Winter, Particle erosion of ductile metals: A mechanism of material removal, Wear, 27 (1974) 121-128.

[8]G. Sundararajan, The depth of plastic deformation beneath eroded surfaces: the influence of impact angle and velocity, particle shape and material properties, Wear, 149 (1991) $129-153$.

[9] Siddhartha and RenuBisht, A modified approach for better prediction of erosion wear of materials: redefining the paradigms, Materials and Design 47 (2013) $395-407$

[10] I.Finnie, Some observation on the erosion of ductile metals, Wear, 19 (1972) 81-90.

[11] T. Deng et. al, the influence of particle rotation on the solid particle erosion rate of metals, Wear 256 (2004) 1037-1049 